\title{
The five main influencing factors on lidar errors in complex terrain
}

\author{
Tobias Klaas ${ }^{1}$, Stefan Emeis ${ }^{2,3}$ \\ ${ }^{1}$ Fraunhofer Institute for Energy Economics and Energy System Technology (IEE), Kassel, 34419, Germany \\ ${ }^{2}$ Institute of Geophysics and Meteorology, University of Cologne, Germany \\ $5 \quad{ }^{3}$ Institute of Meteorology and Climate Research, Karlsruhe Institute of Technology, Germany \\ Correspondence to: Tobias Klaas (tobias.klaas@iee.fraunhofer.de)
}

\begin{abstract}
.
Light detection and ranging (notably Doppler lidar), has become a valuable technology to assess the wind resource at hub height of modern wind turbines. However, because of their measurement principle, common wind profile Doppler lidars suffer from errors at complex terrain sites.

This study analyses the impact of the five main influencing factors at lidar measurement errors in complex terrain, i.e. orographic complexity, measurement height, surface roughness and forest, atmospheric stability and half-cone opening angle, in a non-dimensional, model-based parameter study.

In a novel approach, the lidar error $\varepsilon$ is split up into a part $\varepsilon_{c}$, caused by flow curvature at the measurement points of the lidar 15 and a part $\varepsilon_{s}$, caused by the local speed-up effects between the measurement points. This approach, e.g., allows for a systematic and complete interpretation of the influence of the half-cone opening angle $\varphi$ of the lidar. It also provides information about the uncertainty of simple lidar error estimations that are based on inflow and outflow angles at the measurement points.

The model-based parameter study is limited to two-dimensional Gaussian hills with hill height $H$ and hill half-width $L$. $H / L$ and $z / L$, with $z$ being the measurement height, are identified as the main scaling factors for the lidar error. Three flow models

20 of different complexity are used to estimate the lidar errors. The outcome of the study provides manifold findings that enable an assessment of the applicability of these flow models.

The study clearly shows that orographic complexity, roughness and forest characteristics, as well as atmospheric stability, have a significant influence on lidar error estimation. Based on the error separation approach it furthermore allows for an in-depth analysis of the influence of reduced half-cone opening angles.

25 The choice and parameterization of flow models and the design of methods for lidar error estimation are found to be essential to achieve accurate results. The use of a RANS CFD model in conjunction with an appropriate forest model is highly recommended for lidar error estimations in complex terrain. If atmospheric stability variation at a measurement site plays a vital role, it should also be considered in the modelling. When planning a measurement campaign, an accurate estimation of the prospective lidar error should be carried out in advance to decrease measurement uncertainties and maximize the value.
\end{abstract}


https://doi.org/10.5194/wes-2021-26

Preprint. Discussion started: 29 April 2021

(C) Author(s) 2021. CC BY 4.0 License.

Vertical profiling monostatic Doppler lidars are by far the most often used lidar systems in wind energy applications because they are readily available, flexible and easy to use even at remote locations (Clifton et al., 2018; Gottschall et al., 2011; Klaas et al., 2015).

Due to their principle of measurement, common Doppler lidar profiles suffer from erroneous wind vector reconstruction in

35 inhomogeneous flow conditions that are usually found at complex terrain sites (Bradley et al., 2015). However, many wind farms are nowadays planned at such sites (Callies, 2014). It is, therefore, necessary to test lidars at these sites to assess their applicability, identify challenges, and find solutions in order to be able to keep measurement uncertainty on acceptable levels. The most promising approach to account for their lack of accuracy at complex terrain sites is the application of wind flow models (Bradley et al., 2015). Different studies on this approach are considered in the following literature overview that is a summary of the literature study carried out within the dissertation of the author (Klaas, 2020). The literature review aims at identifying the most important influencing factors on the lidar error, which are then concluded at the end of the introductory chapter.

In order to be able to reconstruct the horizontal wind speed, Doppler lidars measure the radial velocity at different locations in

45 the atmosphere. Under the assumption of equivalent wind speed at these locations (so-called "homogeneous flow assumption"), simple trigonometric functions can be used to calculate the horizontal wind speed. This assumption is not valid for measurement sites with significant spatial changes in wind speed, e.g. complex terrain sites (Courtney et al., 2008; Clive, Peter J. M., 2008).

One of the first relevant comparisons between a lidar and a $100 \mathrm{~m}$ mast was carried out by Antoniou et al. (2007). A ZephIR

50 lidar was placed at a complex terrain test station in Greece. While showing correlation comparable to flat terrain studies on the one hand (e.g. Smith et al., 2006), a significant underestimation of the wind speed by the lidar was observed on the other hand. Courtney et al. (2008) state that errors in the determination of mean wind speed in the order of 5-10\% are not uncommon for complex terrain sites. As a solution, they propose to reduce the lidar cone angle from $30^{\circ}$ to $15^{\circ}$ in order to reduce flow complexity between the measurement points.

55 A first attempt to explain and model the error of monostatic remote sensing instruments in complex terrain (lidar and sodar) is presented by Bradley (2008). He applies a simple two-dimensional potential flow model to estimate the wind flow and uses the model results to correct the error due to the homogeneous flow assumption. Depending on the shape of the hill and the measurement height, he finds sodar errors between 5 and $20 \%$ for a cone angle of $20^{\circ}$. Contrary to his hypothesis (and the one from Courtney et al. (2008)), there is no significant increase in the errors when increasing the cone angle to $30^{\circ}$ (which is 60 typical for most lidars).

Bingöl et al. (2009) study the lidar error at two complex terrain sites in Greece. Here the lidar errors of a ZephIR reach up to a magnitude of $10 \%$ depending on wind direction and for heights between 30 and $80 \mathrm{~m}$. An algorithm is implemented into 
https://doi.org/10.5194/wes-2021-26

Preprint. Discussion started: 29 April 2021

(c) Author(s) 2021. CC BY 4.0 License.

\section{(c) (i)}

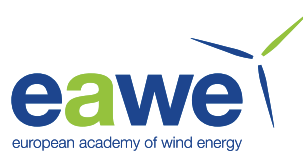

WAsP Engineering (WEng) that uses the model results to calculate an estimation for the lidar error at the two sites. Although the model is simple and limited to low slopes only, the estimated errors fit well to the observed results for the main wind

directions. For the wind directions with increased slope (south-west), the results do not fit very well, which is attributed to limitations in WEng. In a simple, two-dimensional analytical consideration, Bingöl et al. (2009) also show that the lidar error is not dependent on the cone angle, but only on the horizontal homogeneity of the flow. These analytical findings are verified by Foussekis (2009), who compares the results for the ZephIR and two Windcube lidars, one with a $30^{\circ}$ and one with a $15^{\circ}$ cone angle against a $100 \mathrm{~m}$ mast at the complex terrain CRES test station in Greece. Here, an underestimation of about $6 \%$ is

70 found for all three lidars, independent of measurement principle ( $\mathrm{CW}$ and pulsed) and cone angle $\left(15^{\circ}\right.$ or $\left.30^{\circ}\right)$. Additionally, the study states that the lidar error is independent of height at this site (Foussekis, 2009).

For the ZephIR and the Leosphere Windcube lidar, lidar error estimation methods using the Reynolds-averaged Navier-Stokes (RANS) computational fluid dynamics (CFD) models WindSim and Meteodyn WT were developed and tested over the years (Harris et al., 2010; Meissner and Boquet, 2011; Bezault et al., 2012; Jokela et al., 2013; Kim and Meissner, 2017). The lidar error estimation approaches are comparable to that proposed by Bingöl et al. (2009). The results emphasize that WEng tends to overestimate the lidar error, especially for steep slopes. The CFD code provides a better estimate for the inhomogeneous flow above the terrain and corrected lidar data mostly shows a better agreement between to the reference data after application of the CFD correction. The authors conclude that these findings show the limitations of the WEng model in terms of terrain complexity (compare e.g. Harris et al., 2010). Other studies rely on different CFD software to correct for the lidar error. For example, Boquet et al. (2010) use a CFD model called "ARIA" to correct the lidar error at a complex site for three different heights (56, 78 and $100 \mathrm{~m}$ ). For all three heights, the correction significantly reduces the bias between lidar and mast.

Contrary to that, based on his previous study, Bradley (2012) extends his potential flow model to sodar and lidar data on a simple two-dimensional hill and an escarpment. Additionally, the results from the simple model are compared to more advanced CFD models (WindSim and OpenFOAM) from Behrens et al. (2012) at two different complex terrain sites in

85 Scotland and New Zealand. Results show that the simple potential flow model is mostly sufficient to estimate the lidar error at these sites (Bradley, 2012), although there are some cases where CFD provides better results (Behrens et al., 2012). For the Windcube v2, Leosphere introduced a proprietary method called "flow complexity recognition" (FCR) to correct for the lidar error in complex terrain already during the measurement. First, the principle of this method was not revealed due to confidentiality (Foussekis, 2011, p. 10). With FCR the bias between lidar and mast is significantly reduced in the study of

90 Foussekis (2011). FCR was also tested by Wagner and Bejdic (2014) at a complex terrain site. Here, wind speeds are underestimated by $4 \%$ in default mode. With FCR turned on, there is a slight overestimation of $1.5 \%$, which means at this site FCR over-corrects for the lidar error. According to the authors, this has also been observed in previous studies (Wagner and Bejdic, 2014). In an inter-comparison of FCR results for sites of various complexities, this effect is also evident for several sites, although the magnitude of the bias is mostly reduced by FCR. It is interesting to note that in this study, FCR heavily over-corrects the measurement data at the highly-complex site by $20 \%$, which implicates that FCR might not be suitable for this site (Krishnamurthy and Boquet, 2014). In 2017, Leosphere revealed the method behind FCR in a detailed technical report 
https://doi.org/10.5194/wes-2021-26

Preprint. Discussion started: 29 April 2021

(c) Author(s) 2021. CC BY 4.0 License.

(Leosphere, 2017). It uses the 3D wind field model "SWIFT" to calculate the wind flow in the closer proximity of the lidar to estimate the lidar error. It is, therefore, comparable to the other model-based correction approaches. Leosphere also states that FCR is limited to moderately complex terrain and low surface roughness (Leosphere, 2017). In its complexity, the model is comparable to WEng, which might explain its incapability to be applied at very complex and forested sites.

A systematic review over the at that time available studies and open research questions regarding remote sensing in complex terrain is given in Bradley et al. (2015). The study concludes that simple models, e.g., potential flow models, can often correct for the lidar error acceptably well. However, as soon as recirculation or detached flow situations occur, more sophisticated models are needed that are capable of modeling those flow features. Also, more detailed characteristics of the atmospheric boundary layer flow (e.g., low-level jets or atmospheric stability) are so far not treated in the context of remote sensing in complex terrain (Bradley et al., 2015).

Based on this literature review, it becomes obvious that the performance of lidar error estimation approaches based on flow modelling is heavily dependent on the actual site characteristics. Five governing influencing factors on the lidar error in complex terrain must be considered: Orographic complexity, terrain roughness and vegetation, atmospheric stability, measurement height and half-cone opening angle.

In all available studies on lidar-mast comparisons at complex terrain sites, it is found that the lidar error is dependent on orographic complexity. Lidar errors measured at sites of different complexity and for distinct wind directions vary in magnitude and can either be negative or positive (e.g Bingöl, 2009; Antoniou et al., 2007). The respective literature lacks a systematic

115 comparison of lidar measurement accuracy concerning different orographic complexities. Existing experimental studies mostly focus on the results from a single site. Comparing different studies with sites of different orographic complexity is difficult, as the used anemometry and equipment, as well as the methods and definitions for data preparation and analysis, are usually not the same. In addition to that, it is not always the same type or even technology of wind lidar that is used for the evaluation, and the results (e.g., from pulsed and continuous-wave lidars) are not directly comparable.

120 Measurement sites do not only differ in terms of orographic complexity but also in land cover and, therefore, terrain roughness and vegetation. Many complex terrain sites that are used for current wind energy projects are located in forested terrain (Callies, 2014). It is well known that terrain roughness and especially forest heavily influence the wind flow above the terrain (Belcher et al., 2008; Finnigan and Belcher, 2004). Roughness elements and forest induce turbulence and shear in the wind profile or even enhance the formation of flow separation zones (Belcher et al., 2012; Shannak et al., 2012). With this in mind, the assessment of the individual influence of single parameters of different sites on the actual lidar error is challenging. Comparing the accuracy of lidar measurements between sites of different orographic complexity, for example, is hindered by the influence of terrain roughness and vegetation. For example, results from Klaas et al. (2015) at a forested site show much smaller lidar errors than those found in Bingöl et al. (2009) or Foussekis (2011), which are both not forested. 
https://doi.org/10.5194/wes-2021-26

Preprint. Discussion started: 29 April 2021

(c) Author(s) 2021. CC BY 4.0 License.

(c) (i)

Nearly all studies have in common that the reference masts are lower than or equal to $100 \mathrm{~m}$, as these are common and

economically feasible mast heights. Contrary to that, wind turbines have been increasing in both hub height and rotor diameter, leading to upper tip heights of modern wind turbines in the range of $200 \mathrm{~m}$ (Rohrig, 2018).

Another aspect that has not yet been treated in literature is the influence of atmospheric stability on lidar measurement accuracy. Although it is stated in a few studies that there might be an effect from this (e.g., Bradley et al. (2015)), the author is not aware of any piece of work that examines the dependence of lidar measurement accuracy in terms of varying atmospheric stability in any kind. However, there is a significant influence of atmospheric stability on the wind profile and the wind flow over or around hilly terrain (Ross et al., 2004; Leo et al., 2016), that might very well influence lidar measurement accuracy. Within the context of measurement height, the half-cone opening angle of the lidar is another factor that must be considered. With increasing measurement height, the distance between the measurement points of the lidar also increases significantly. Courtney et al. (2008) are proposing to reduce the half-cone opening angle from $30^{\circ}$ to $15^{\circ}$ in order to reduce the lidar error in complex terrain. This suggestion is interrogated and tested experimentally by Bingöl et al. (2009) and Foussekis (2009), who come to the conclusion that the half-cone angle does not influence the lidar error. Also, Bradley et al. (2015) derive lidar error estimations that are solely dependent on flow curvature and independent of the half-cone opening angle. However, these findings are based on the assumption of symmetric flow and constant flow curvature. For flow simulations that consider surface roughness and forest as well as atmospheric stability, these assumptions are not necessarily valid (compare e.g. Belcher et al. (2008) and Ross et al. (2004)).

The study presented here aims at providing a guideline for lidar users in the wind energy sector to assess the applicability of lidars at complex terrain sites. Although there are some studies that compare lidar correction with different flow models in complex terrain, a holistic examination of the limits of these models concerning their ability to estimate the lidar error does not exist. The overall aim is a systematic expansion of knowledge and understanding of the applicability and limits of current Doppler lidars for wind measurements in complex terrain under consideration of the above-explained influencing factors. To understand their particular influence, it is vital to examine them separately.

The study firstly analyses the influence of the most governing factors on lidar errors in complex terrain in a systematic way revealing the actual influence and importance of each. Secondly, it combines these findings to an overall perspective that can be used as a practical guideline for the application of lidars in the terrain of various complexities. To the knowledge of the author, there is no comprehensive assessment like this so far. The findings of Klaas et al. (2015) were a trigger to intensify research on model parameterization in the context of lidar error estimation, which is done in the present study.

160 Moreover, due to the model-based approach of the study, it can also answer questions of the applicability and limitations as well as the strengths and weaknesses of the different flow models that are used to estimate the lidar error. It, therefore, provides 
helpful guidance on the necessary complexity of the flow model to be used for lidar error estimation in a particular situation or at a specific site.

Especially the work on atmospheric stability and its impact on the lidar error in complex terrain has not been treated in literature

165 so far. The study therefore closes a gap between the knowledge about the influence of atmospheric stability from a meteorological perspective on the one hand and its implications on the lidar error on the other hand.

Furthermore, the lidar error estimation follows a novel approach where the lidar error is separated into its two main parts: Lidar error due to flow curvature effects and lidar error due to speed-up effects. A comparable approach was not found in the relevant literature. This approach gives a more detailed and structured insight into the flow effects that cause lidar errors in complex terrain. Especially the question, if the lidar half-cone opening angle is an important parameter that has to be considered, can be answered by this approach.

\section{Methods}

As already stated in the introduction, one of the main methods to correct for lidar errors in complex terrain is based on the use

175 of computational wind flow models. However, using such models, e.g. for wind resource assessments, presumes knowledge about the optimal parameterization to fit the model to the considered site and measured wind profiles. From that, model results can be used for vertical and horizontal extrapolation of the wind conditions (Ayotte, 2008). From geodata, maps and site visits, information about land-use is gathered and transferred into surface parameters such as roughness length and forest model parametrizations. Based on the experience of the consultant and literature knowledge these are used to set up the flow model.

Wherever possible, modelled wind profiles are compared to those from measurements available at the site in order to improve the accuracy of the model results (e.g. Palma et al., 2008). If only lidar measurements are available at a complex terrain site, the measured data is affected by the complex terrain lidar error. Because of that, additional uncertainties occur when using this data for model validation. It is necessary to estimate the uncertainty in the lidar data due to complex terrain before comparing

185 it to the model. Alternatively, a correction of the lidar data can be carried out, but then the uncertainty of this correction must be estimated as well (FGW e.V., 2017; Clifton et al., 2018).

For the latter, an evaluation of uncertainties of currently used correction methods is necessary. Recent studies only state the "best" results that can be achieved by using a parameter set optimized for the actual measurement site. In order to do so, the

model parameterization has either been validated against a measured wind profile from a close-by mast or the accuracy of the lidar error correction method itself is validated by a mast-lidar comparison at the site (e.g., Klaas et al., 2015; Bingöl et al., 2009). To the knowledge of the author, there is no systematic evaluation available that analyses the influence of model 
https://doi.org/10.5194/wes-2021-26

Preprint. Discussion started: 29 April 2021

(C) Author(s) 2021. CC BY 4.0 License.

parameterization on the results of lidar error corrections. Furthermore, there is no comprehensive uncertainty assessment of the lidar error estimation.

In the following, the results from a parameter study are presented that systematically compares correction results based on three different common flow models and different parameter settings to accomplish a systematic understanding of flow model parameter variations on the result lidar error estimations.

200 Wind flow is modelled above simplified, two-dimensional Gaussian hills with hill height $\mathrm{H}$ and hill half-width L (see Figure 1 and Table 1). In order to make the results applicable to, e.g. arbitrary hill geometries and measurement heights, the results are presented in a non-dimensional way wherever possible. Under consideration of the measurement height $z$, two nondimensional parameters are derived that allow for a well-arranged presentation of the results: $H / L$ as a parameter that expresses orographic complexity and $z / L$ that relates the measurement height to the actual size of the hills. Further parameters that are analysed are terrain roughness $z_{0}$, forest height $h$ and forest density, atmospheric stability and half-cone opening angle $\varphi$ of the lidar.

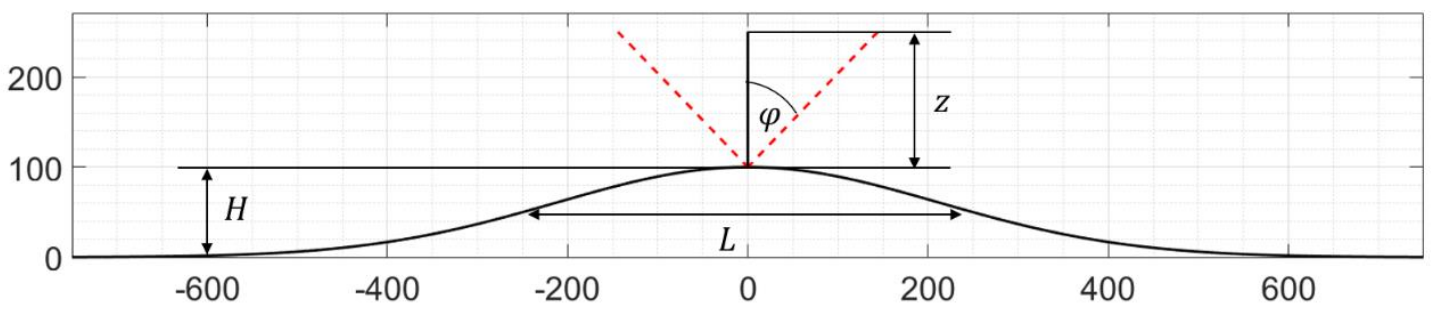

Figure 1: Exemplary sketch of a Gaussian hill used in the parameter study. Each hill is defined by its height $H$ and its hill half-width $L$. A representation of the lidar geometry for measurement height $z$ and a half-cone opening angle $\varphi$ is shown as well. In this example, $H$ is $100 \mathrm{~m}$ and $L$ is $250 \mathrm{~m}$ resulting in an $H / L$ ratio of 0.4 and for the measurement height $z$ of $150 \mathrm{~m}$ in a $z / L$ ratio of 0.60 .

Table 1: Set of Gaussian hill geometries used in the parameter study. The table provides information about the hill height $H$, the hill half-width $L$ and the corresponding ratio $H / L$. Addtionally the maximum slope (maximum terrain inclination) at the flanks of the hill is calculated for the four different used ratios.

\begin{tabular}{|c|c|c|c|c|c|c|c|c|c|}
\hline H/L & $\mathbf{L}[\mathbf{m}]$ & 50 & 100 & 150 & 200 & 250 & 500 & 750 & Max. slope \\
\hline 0.1 & \multirow{4}{*}{$\mathbf{H}[\mathrm{m}]$} & 5 & 10 & 15 & 20 & 25 & 50 & 75 & 0.07 \\
\hline 0.2 & & 10 & 20 & 30 & 40 & 50 & 100 & 150 & 0.14 \\
\hline 0.3 & & 15 & 30 & 45 & 60 & 75 & 150 & 225 & 0.21 \\
\hline 0.4 & & 20 & 40 & 60 & 80 & 100 & 200 & 300 & 0.29 \\
\hline
\end{tabular}


Three different flow models are used that differ in terms of complexity. This enables to analyse the influence of additional parameters and model extensions (e.g. a forest model) in reference to the simpler approaches.

First, the simple potential flow model from Bradley (2008) is used to analyse the terrain effects on the wind flow over twodimensional Gaussian hills. The model is frictionless and symmetric and does therefore not cover any effects of roughness, forest or other more complex properties of the atmosperic win flow. It is used as a baseline or reference case to depict the influence of the diverse parameters on the results of the other, more complex models. The model is implemented and adapted to the correction approach described below.

225 The second model that is used, WEng, is based on linearized Navier Stokes Equations and a very common model for wind energy applications (Mann et al., 2002). It is able to model the influence of roughness on the wind flow. However, with regards to the available literature, the model is recommended to be used only for slightly complex terrain and there is no forest model implemented (Mann et al., 2002; Dellwik et al., 2006). A displacement height has not been used within this study. The model is also used by Bingöl et al. (2009), who provide a script with their correction algorithm. This script is modified in order to adapt it to the correction approach used in the present study.

The third model, Meteodyn WT, is a RANS CFD model, that is able to model roughness and forests (Meteodyn, 2014). It has also a simplified method to account for atmospheric stability. This model is more and more used for wind resource assessments and is considered to be more appropriate for complex and forested sites. More details about the model can either be found in technical reports from the developer (Meteodyn, 2007) or the dissertation of the author (Klaas, 2020). For Meteodyn WT there is also a proprietary lidar correction method available. However, this method is not used in the present study, but the correction approach described below is implemented and applied to the flow model results from Meteodyn WT.

For the two models WEng and Meteodyn WT surface and flow parameters have been varied according to Table 2. Three different roughness legnths were analysed for both models, ranging from smooth bare soil surface caracteristics to bushes. For Meteodyn WT the forest model has been used with three heights of 10, 20 and $30 \mathrm{~m}$. Additionally the forest density has been varied (low, medium and high) and detailed results on this can be found in Klaas (2020).

Table 2: Roughness lengths $z_{0}$ of the different roughness maps that were used in the flow models. The purpose of the maps is also given, which includes the corresponding tree heights in Meteodyn WT. Surface characteristics were taken from Troen (1989).

\begin{tabular}{|l|l|l|l|l|}
\hline $\begin{array}{l}\text { Roughness } \\
\text { length }[\mathbf{m}]\end{array}$ & $\begin{array}{l}\text { Surface } \\
\text { characteristics }\end{array}$ & Tree height [m] & Used in WEng & Used in Meteodyn WT \\
\hline 0.005 & bare soil & - & yes & yes \\
\hline 0.100 & farmland & - & yes & yes \\
\hline 0.500 & bushes, suburbs & 10 & yes & yes (forest and roughness) \\
\hline 1.000 & city, forest & 20 & no & yes (forest) \\
\hline 1.500 & city, forest & 30 & no & yes (forest) \\
\hline
\end{tabular}


https://doi.org/10.5194/wes-2021-26

Preprint. Discussion started: 29 April 2021

(c) Author(s) 2021. CC BY 4.0 License.

(c) (1)

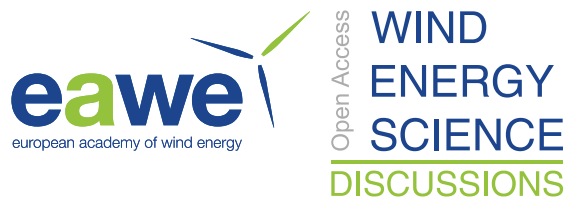

As shown in Table 3, the atmospheric stability model in Meteodyn WT has also been used to change the stability class which is attributed to a certain Obhukov length $L_{*}$ in the model. This was done for a low roughness case, a case with high roughness and a forested case, to assess the influence of atmospheric stability for different surface characteristics. Only results for the latter are shown exemplaryly within the this study. More detailed results can be found in Klaas (2020). All parameterizations 250 were modelled for the different hill geometries given above in order to analyse the overall influence for the available combinations of $H / L$ and $z / L$.

Table 3: Atmospheric stability classes from Meteodyn WT (Meteodyn, 2014).

\begin{tabular}{|l|l|l|}
\hline Stability class & Stability & $\boldsymbol{L}_{*}[\mathbf{m}]$ \\
\hline 0 & Very unstable & -80 \\
\hline 1 & Unstable & -500 \\
\hline 2 & Neutral & 10.000 \\
\hline 3 & Slightly Stable & 1.500 \\
\hline 4 & Stable & 800 \\
\hline 5 & Stable & 500 \\
\hline 6 & Stable & 300 \\
\hline 7 & Very Stable & 200 \\
\hline 8 & Very Stable & 130 \\
\hline 9 & Strongly Stable & 60 \\
\hline
\end{tabular}

255 A definition of the lidar error and its parts can be derived based on the measurement geometry of common Doppler wind lidars, such as the Leosphere Windcube. Figure 2 defines the measurement geometry and the coordinate system, as well as the azimuth angle $\theta$ and the half-cone opening angle $\varphi$. It also illustrates the three dimensional measurement geometry with four measurement points. This measurement geometry has been simplified to two-dimensional flow from west to east. 
https://doi.org/10.5194/wes-2021-26

Preprint. Discussion started: 29 April 2021

(c) Author(s) 2021. CC BY 4.0 License.

(c) (i)
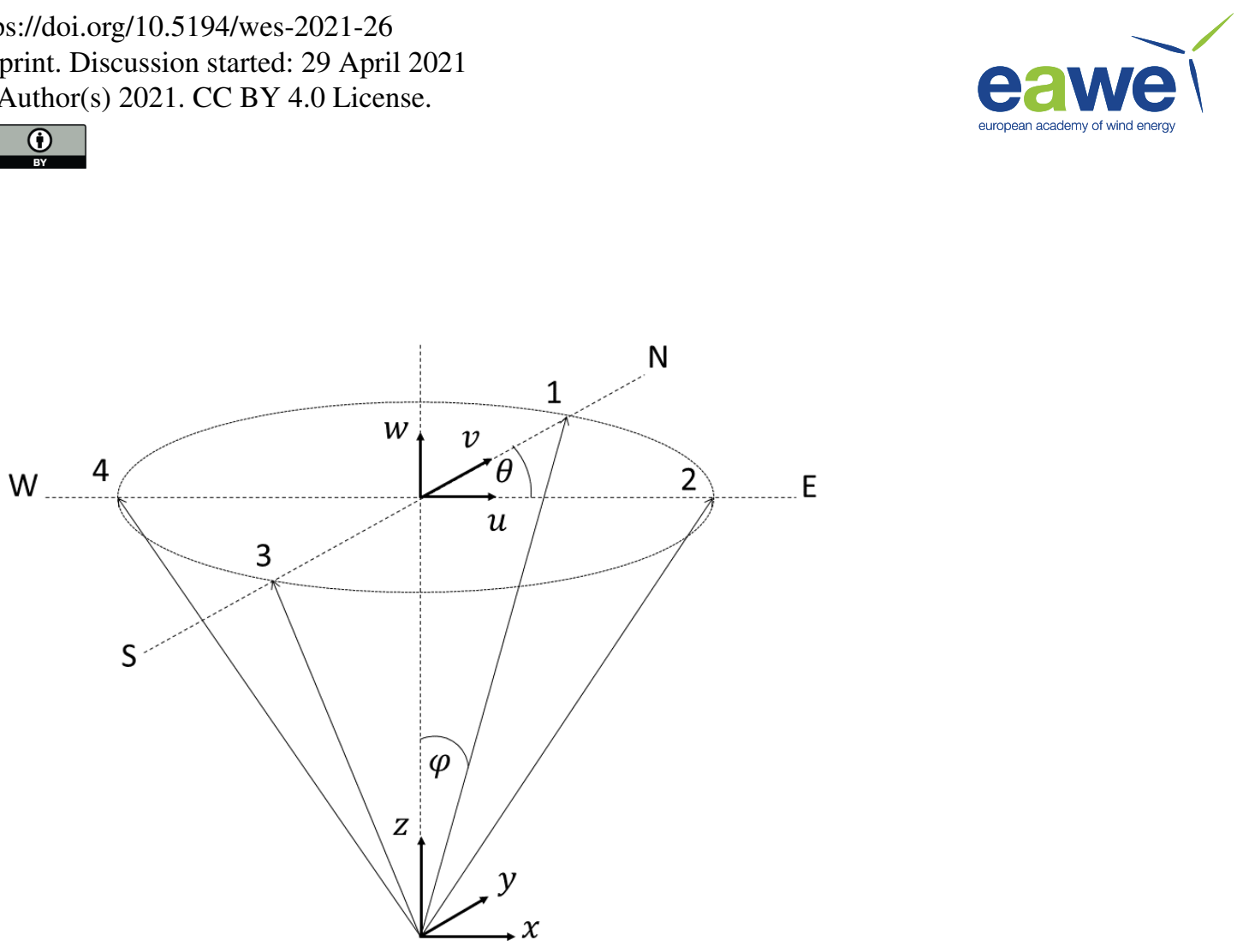

Figure 2: Lidar measurement geometry and definitions of the local coordinate system $(x, y, z)$ and the wind vector components $(u, v, w)$ as well as the half-cone opening angle $\varphi$ and the azimuth angle $\theta$ (here for the second measurement location, $90^{\circ}$ from the north). The measurement locations are numbered starting from North $(\mathrm{N})$ clock-wise to West $(\mathrm{W})$. The measurement locations are shown for an example measurement height at a plane defined by the circle. This measurement geometry equals the one that is used in the Leosphere Windcube v1. In the successive version Windcube $v 2$, a fifths measurement location has been added with $\varphi=0$ directly above the origin at measurement height.

A typical complex terrain flow case is shown in Figure 3 with a lidar placed on top of an abritrary hill. The reconstructed horizontal wind speed $\hat{u}$ can be calculated based on the two radial wind speeds and the half-cone opening angle. However, for a given measurement height $z$ it can be noted, that the inflow wind speed at the western measurement point is tilted upwards and the outflow wind speed at the eastern measurement point is tilted downwards. The flow inclination, i.e. the vertical wind speed component, contributes to the radial wind speed and therefore introduces and error component. Additionally, due to the speed-up of the wind speed between the two measurement points and the measurement location at measurement height directly above the lidar an additional error occurs. 

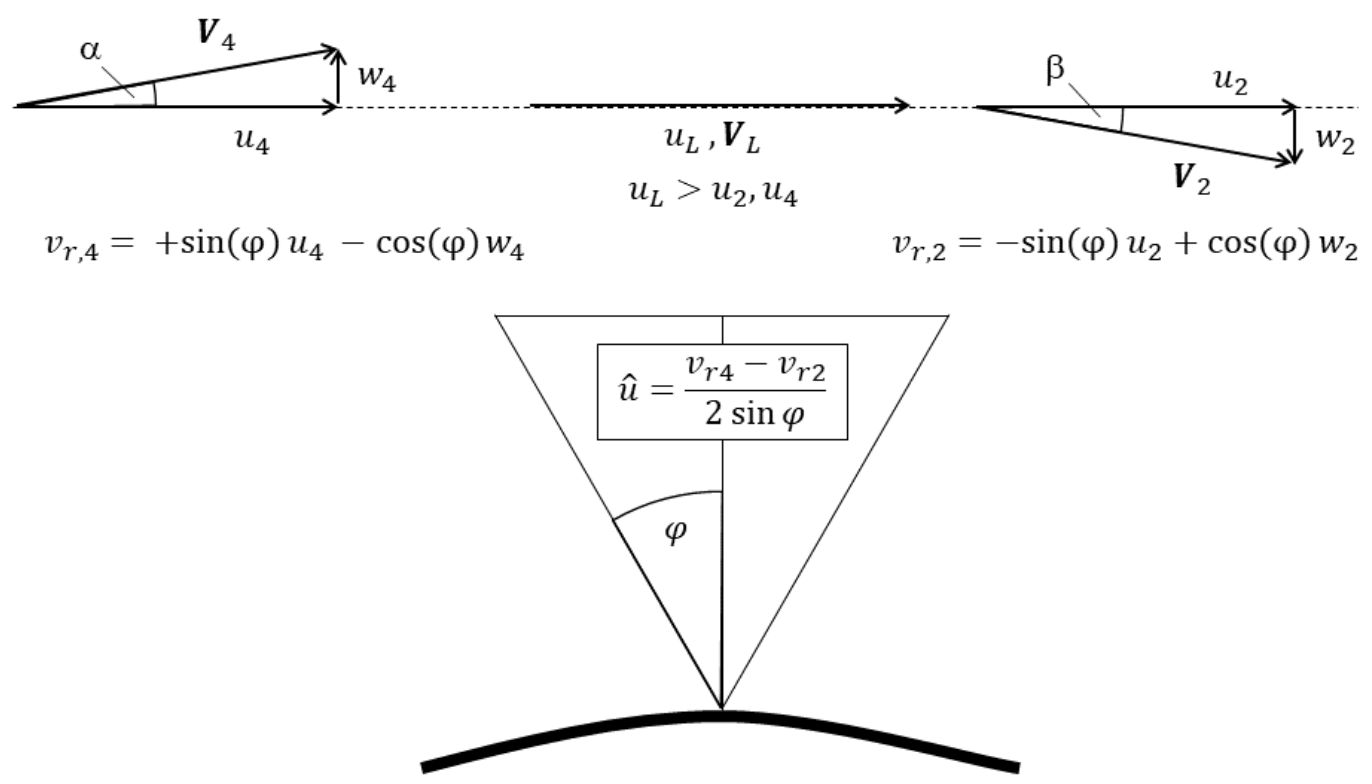

Figure 3: Generic flow case with a lidar placed on a hill-top. As a typical complex terrain example, this case shows a lidar placed on top of a hill within symmetric flow conditions. The changing vertical wind speed component introduces a lidar error. Additionally, there is a speed-up effect on the horizontal component, which causes a part of the total lidar error.

Based on the above-given explanations, the lidar error $\varepsilon$ for the two-dimensional case can generally be defined as follows:

$$
\varepsilon=\frac{\hat{u}-u_{L}}{u_{L}}=\varepsilon_{c}+\varepsilon_{s}
$$

with $\hat{u}$ being the reconstructed wind speed and $u_{L}$ the actual horizontal wind speed at the reconstruction point. Following this definition, an underestimation of the actual wind speed at the reconstruction point will lead to a negative lidar error and an overestimation will lead to a positive lidar error. In order to separate the two effects, the lidar error can be divided into a part being caused by flow curvature $\left(\varepsilon_{c}\right)$ and another part due to speed-up effects $\left(\varepsilon_{s}\right)$. As presented in the results chapter, this distinction will give insight into the influence of the half-cone angle on the lidar error.

The equation for wind vector reconstruction can be rewritten for the two-dimensional case as follows (compare Figure 3):

$$
\hat{u}=\frac{v_{r, \text { in }}-v_{r, \text { out }}}{2 \sin \varphi}=\frac{V_{\text {in }} \sin (\varphi-\alpha)+V_{\text {out }} \sin (\varphi+\beta)}{2 \sin \varphi}
$$

Here the radial wind speeds left and right from the lidar (inflow and outflow) are referenced to as $v_{r, i n}$ and $v_{r, o u t}$ and the magnitude of the wind vector at the same points as $V_{\text {in }}$ and $V_{\text {out }}$. The inflow and outflow inclination angles of the flow are defined as $\alpha$ and $\beta$ and combined with the half-cone opening angle of the lidar $\varphi$. 
https://doi.org/10.5194/wes-2021-26

Preprint. Discussion started: 29 April 2021

(c) Author(s) 2021. CC BY 4.0 License.

(c) (i)

For simplification of the above-given equation (2), the following relationship can be derived:

$$
u_{L}=\frac{u_{\text {in }}+u_{\text {out }}}{2}=\frac{V_{\text {in }} \cos \alpha+V_{\text {out }} \cos \beta}{2}
$$

295

By making use of this equation and by defining the factor $k=\frac{V_{\text {out }}}{V_{\text {in }}}$ equation (2) can be written as:

$$
\hat{u}=u_{L}\left(1-\frac{1}{\tan \varphi} \frac{\sin \alpha-k \sin \beta}{\cos \alpha+k \cos \beta}\right)
$$

Neglecting changes in the magnitude of wind speed between the two measurement points here (they will be considered in the second part of the error equation later) by assuming $k=1$, results in an equation that is independent of the actual wind speed, but only dependent on geometric properties of the wind flow and the lidar:

$$
\varepsilon_{c}=-\frac{\tan \frac{\alpha-\beta}{2}}{\tan \varphi}
$$

And, with $\alpha=\beta$, as it is the case in symmetrical flow situations the equation reduces to

$$
\varepsilon_{c}=-\frac{\tan \alpha}{\tan \varphi}
$$

The speed-up of the horizontal wind speed component between a measurement location $i$ and the reconstruction point can be 305 written as

$$
\Delta u=u_{L}-u_{i}
$$

Keeping in mind that the speed-up between both, the inflow and the outflow measurement point and the reconstruction point have to be considered, the lidar error due to speed-up can be defined by

$$
\varepsilon_{s}=\frac{u_{\text {in }}+u_{\text {out }}}{2 u_{L}}-1
$$

310 Here the difference between inflow and outflow horizontal component of the wind flow is considered as $u_{\text {in }}$ and $u_{\text {out }}$.

Combining equations (6) and (8) leads to the equation used for the assessment of the total lidar error due to complex terrain in this study:

$$
\varepsilon=\left[-\frac{\tan \frac{\alpha-\beta}{2}}{\tan \varphi}\right]+\left[\frac{u_{\text {in }}+u_{\text {out }}}{2 u_{L}}-1\right]
$$


https://doi.org/10.5194/wes-2021-26

Preprint. Discussion started: 29 April 2021

(C) Author(s) 2021. CC BY 4.0 License.

(c) (i)

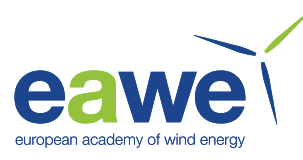

315 In the results section, the lidar error $\varepsilon$ and also its parts due $\varepsilon_{c}$ (flow curvature) and $\varepsilon_{s}$ (speed-up) are usually plotted against the ratio of measurement height over the hill half-width $z / L$. By this, it is possible to extract results for different measurement height as well as different hill dimensions from a single non-dimensional figure. The amount of terrain inclination is in most figures shown for groups of a constant ratio of hill height over the hill half-width $H / L$. In reference to Table 1 , mainly four of these groups are analyzed for slight slopes up to high slopes in the order of 0.3 .

\section{Results and Discussion}

In the following, the main results of the non-dimensional parameter study are presented, starting with those from the potential flow model. Additionally the influence of the half-cone opening angle is analysed based on results from the potential flow model. Then the influence of terrain roughness is shown for both, WAsP Engineering and Meteodyn WT. Finally, exemplary results with regards to the influence of forest height and atmospheric stability are discussed. More detailed and complete results can be found in the dissertation of the author (Klaas, 2020).

\subsection{Influence of orographic complexity and measurement height}

Figure 4 (left) shows the results for the lidar error $\varepsilon$ versus the ratio $z / L$ for four different $H / L$ ranging from 0.1 to 0.4 . With increasing $z / L$, the curves follow a distinct shape: The lidar error constantly increases until it reaches a maximum in the range of $z / L$ between 0.5 and 0.6. The exact position is slightly dependent on the $H / L$ ratio and increases with increasing $H / L$. Then the lidar errors starts to decrease for all $H / L$ ratios. Also, the maximum lidar error significantly increases with increasing terrain inclination. For a $H / L$ ratio of 0.1 , it is slightly larger than $-3 \%$. For a $H / L$ ratio of 0.4 , it reaches up to about $-11 \%$. 
https://doi.org/10.5194/wes-2021-26

Preprint. Discussion started: 29 April 2021

(C) Author(s) 2021. CC BY 4.0 License.

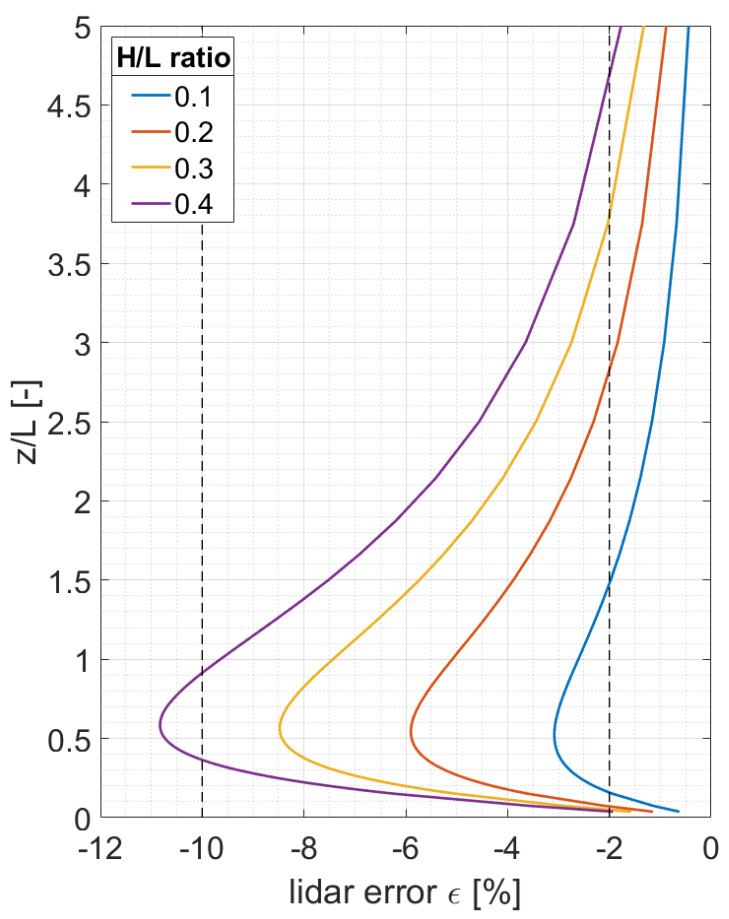

a)

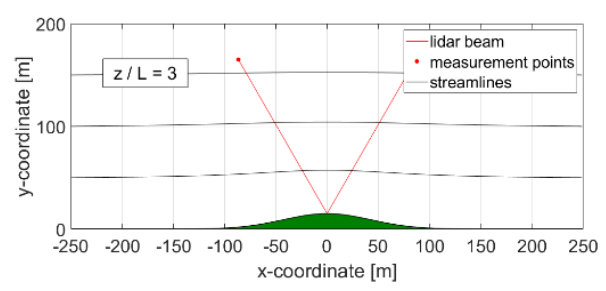

b)

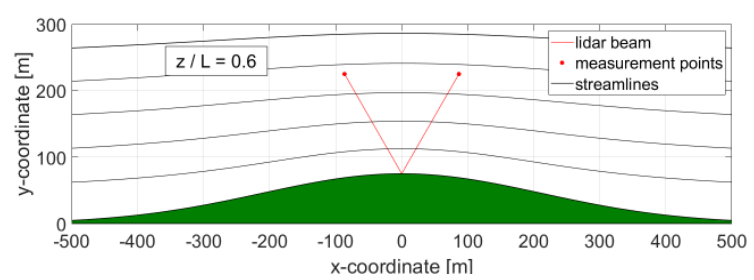

c)

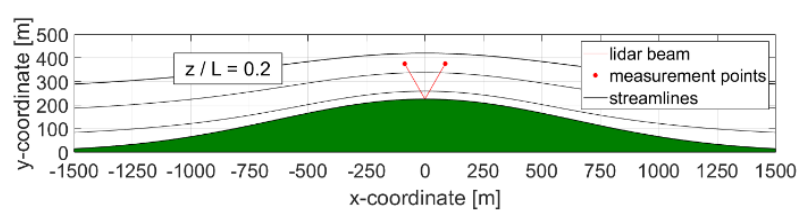

Figure 4: Left: Lidar error $\varepsilon$ in dependence of the ratio $H / L$ between $z / L$ ratios from 0 to 5 . Results are based on the potential flow model. The two dashed lines mark a typical uncertainty of wind measurements (-2\%) and a reasonable limit for acceptable lidar errors in wind resource assessments $(-10 \%)$. Right: Results from the potential flow model for $\mathrm{L}=50 \mathrm{~m}(\mathrm{a}), 250 \mathrm{~m}(\mathrm{~b})$ and $750 \mathrm{~m}(\mathrm{c})$ for an $H / L$ ratio of 0.3 . The lidar position is marked at the top of the hills and the beams are tilted by a half-cone opening angle $\varphi=30^{\circ}$. The measurement points are located at $\mathrm{z}=150 \mathrm{~m}$ above the lidar. The points, therefore, are equal to $\mathrm{z} / \mathrm{L}$ ratios of 3 (a), 0.6 (b) and 0.2 (c).

Figure 4 (left) contains two dashed lines: The $-2 \%$ line marks a typical uncertainty of wind measurements based on cupanemometers as a reference (Basse et al., 2017). Lidar measurement errors below $-2 \%$ are in the same order as uncertainties of mast-based measurement. Such small errors will not add much uncertainty to the wind measurement. However, because lidar errors are systematic, a correction is mandatory also in case of small errors. The -10 \% line marks an approximate upper limit for a reasonable correction of lidar errors in complex terrain, which is based on the estimation that the uncertainty in lidar correction will not allow for a reasonable resource assessment with lidar errors in this magnitude.

From Figure 4 (left), it can be noticed that the $2 \%$ line is crossed for the steepest hills $(H / L$ of 0.4$)$ at a $Z / L$ of about 4.5 and for the lowest slopes $(H / L$ of 0.1$)$ at $z / L$ of 1.5 . For low $z / L$ ratios (broadest hills), the three lines for $H / L$ of $0.2,0.3$ and 0.4 are crossing the $2 \%$ line close together between 0.04 and 0.07 . For the least complex hill, the lidar error already decreases below $2 \%$ at a $z / L$ of 0.16 . 
https://doi.org/10.5194/wes-2021-26

Preprint. Discussion started: 29 April 2021

(C) Author(s) 2021. CC BY 4.0 License.

Following this, it can be concluded that for a small $H / L$ of 0.1 , only a very limited parameter range between $z / L$ of 0.16 and

1.5 is relevant for correction. Additionally, the necessary corrections are relatively small, with maximum errors in the range of $-3 \%$. For more complex terrain and therefore larger $H / L$, a much larger parameter space must be considered. Significant lidar errors can be found for large hills down to a $z / L$ of 0.04 and also very narrow but steep hills in the range of $z / L$ from 2 to 4.5 for $H / L$ between 0.2 and 0.4 . The magnitude of the lidar errors for those terrains is also much higher. The $-10 \%$ line is only crossed by the maximum error for the steepest terrain of $H / L$ of 0.4 cases between $z / L$ between 0.35 and 0.9 .

The righthand side of Figure 4 illustrates three selected Gaussian hills with an $H / L$ ratio of 0.3 and a measurement height $z$ of $150 \mathrm{~m}$. Based on this, the relationship between measurement height and hill size, i.e. hill half-width can be analysed in detail. Increasing $z / L$ ratios can be interpreted in two ways:

First, the hill size decreases for increasing $z / L$ ratio when keeping the measurement height constant. For a given measurement height the maximum lidar error is then found for a hill size with $L$ in the range of 1.6 to 2.0 times $z$. Lidars errors decrease strongly for broader hills (smaller $z / L$ ) and also for more narrow hills (large $z / L$ ).

Second, when keeping $L$ constant, increasing $z / L$ can be interpreted as increasing measurement height. From this perspective, lidar errors are relatively small for low measurement heights and increase strongly up to a $z$ equal to 50-60\% of $L$. Beyond the maximum point, lidar errors decrease continiously until they become insignficant as terrain influence on the wind flow diminishes.

Deduced from these observations, the shape of the lidar error curves can be explained as follows: For very low measurement heights (or very broad hills) both, the local speed-up effects and the flow inclination angles are small and so are the resulting lidar errors. With increasing $z / L$, both effects significantly increase, because either the measurement point distance increases with increasing measurement height or - from the perspective of hill size - the hill becomes more narrow and flow inclination and local speed-up effets in the vicinity of the lidar increase. Then, with $z / L$ increasing above 0.6 , the terrain influence diminishes for increasing measurement heights. From the perspective of terrain scaling, for narrow hills, the lidar measurement points move left and right towards the flanks of the hill and therefore to positions where flow inclination decreases. For very small hills additionally speep-up effects become less important.

\subsection{Separation of the two lidar error parts}

380 As defined in the methods section, the lidar error $\varepsilon$ can be subdivided into a part $\varepsilon_{c}$ caused by flow curvature and a part $\varepsilon_{S}$ caused by speed-up between the measurement points. Figure 5 illustrates $\varepsilon_{c}$ and $\varepsilon_{s}$ next to each other in the same way that $\varepsilon$ is presented above.

The general shape of the four curves is similar to that presented in Figure 4. The maximum errors $\varepsilon_{c}$ (Figure 5, left) are slightly smaller compared to $\varepsilon$. For an $H / L$ ratio of 0.4 , the error is no longer exceeding the $-10 \%$ line. For a $H / L$ of 0.1 , the maximum 
https://doi.org/10.5194/wes-2021-26

Preprint. Discussion started: 29 April 2021

(c) Author(s) 2021. CC BY 4.0 License.

error is about $2.5 \%$. The maximum error is now located between $z / L$ of 0.45 and 0.51 . Also, the point of intersection with the $2 \%$ line on the right-hand side is significantly shifted downwards.

Looking at Figure 5, right, which shows the speed-up part $\varepsilon_{s}$, it becomes obvious that this part is much smaller in magnitude than the curvature part. However, it reaches up to $-1.95 \%$ for a $H / L$ ratio of 0.4 and also the magnitudes for $H / L$ ratios 0.2 and 0.3 are not negligible. The position $z / L$ of the maximum error due to speed-up is between 0.9 and 1.0 . The lidar error caused by speed-up, therefore, shifts the resulting curves for the total lidar error $\varepsilon$ upwards.

For small $z / L$ the share of $\varepsilon_{S}$ of the total lidar error is about $10 \%$. With increasing $z / L$ the share increases up to about $30 \%$. For large $z / L$, i.e. for relatively small or narrow hills, the speed-up part becomes more important in the overall lidar error correction. For small $z / L$, i.e. large hills (or low measurement heights), correction appraoches solely based on flow curvature might be sufficient.
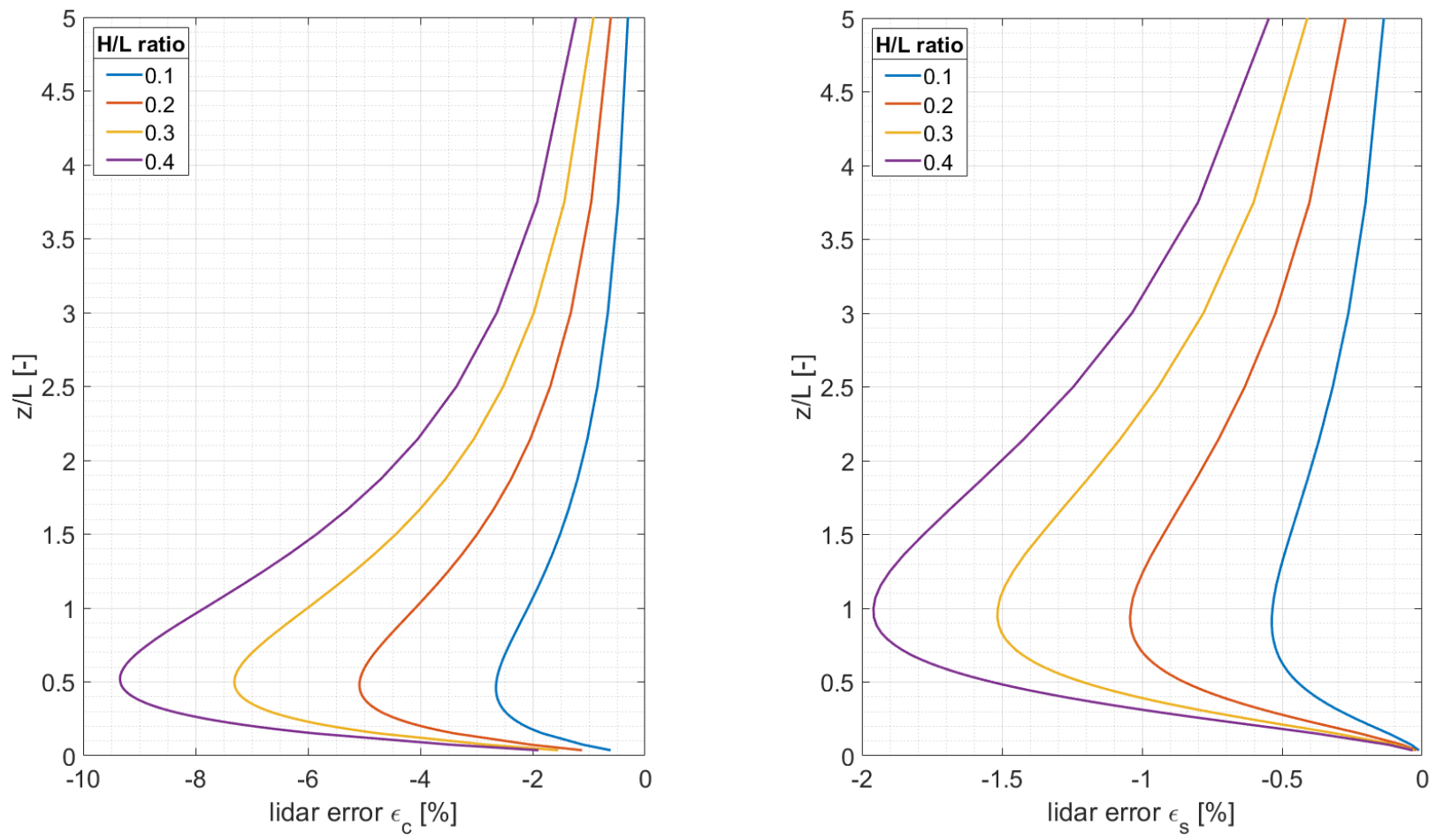

Figure 5: Lidar error $\varepsilon_{c}$ (left) and $\varepsilon_{s}$ (right) in dependence of the ratio $H / L$ between $z / L$ ratios from 0 to 5 . Results are based on the potential flow model. Note the different scaling of the $x$-axes. 
https://doi.org/10.5194/wes-2021-26

Preprint. Discussion started: 29 April 2021

(C) Author(s) 2021. CC BY 4.0 License.

\subsection{Influence of the half-cone opening angle}

400 Figure 6 is illustrating the influence of changing the half-cone opening angle $\varphi$ of the lidar measurement geometry on $\varepsilon, \varepsilon_{c}$ and $\varepsilon_{s}$. To separate and analyze the individual contribution of local speed-up effects and flow inclination angles with varying $\varphi$, the separation of the lidar error is very usefel. Results are presented for the potential flow model only, in order to analyse and explain the basic principle.

Figure 6 (left) shows the lidar error $\varepsilon$ for the four $H / L$ ratios and the three different half-cone opening angles $30^{\circ}, 20^{\circ}$ and $10^{\circ}$.

405 When decreasing the half-cone angle, there is also a slight decrease in the lidar error. This is particularly true for $z / L$ ratios between 0.3 and 1.0, which is in the range of the maximum lidar error. For larger $z / L$ ratios, the influence of $\varphi$ on the lidar error decreases. For small $z / L$, the influence is also only marginal.

Figure 6 (middle and right), which shows the lidar error split up into $\varepsilon_{c}$ and $\varepsilon_{s}$, enables to retrace of the individual contribution of flow curvature and speed-up effects on the total lidar error $\varepsilon$. It becomes obvious that decreasing the half-cone opening

410 angle significantly decreases $\varepsilon_{S}$. While $\varepsilon_{S}$ reaches up to $-2 \%$ for an $H / L$ ratio of 0.4 for a $\varphi$ of $30^{\circ}$, it falls below $-0.25 \%$ for all $H / L$ ratios for an angle of $10^{\circ}$.

Decreasing $\varphi$ has a contrary influence on $\varepsilon_{c}$. While there is almost no influence for the lowest two $z / L$ ratios, there is an increase of $\varepsilon_{c}$ for half-cone angles of $20^{\circ}$ and $10^{\circ}$ when compared to the original $30^{\circ}$. This difference is largest for $z / L$ above 0.5 and persists up to $z / L$ of 3 .

415 The superposition of the two opposing effects results in the total effect on $\varepsilon$ as it is shown in Figure 6 (left).
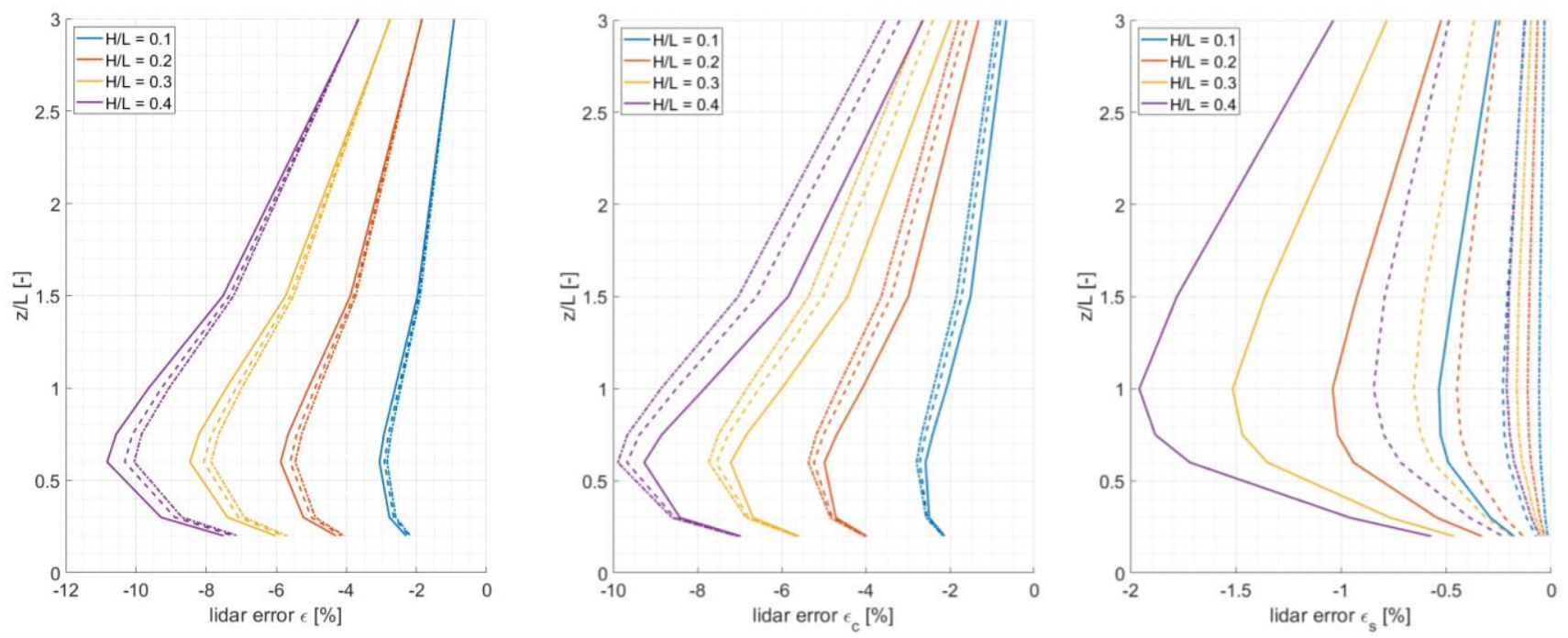

Figure 6: Lidar error $\varepsilon$ (left), $\varepsilon_{c}$ (middle) and $\varepsilon_{s}$ (right) in dependence of the $H / L$ ratio for the half-cone opening angles $\varphi$ of $30^{\circ}$ (solid lines), $\mathbf{2 0}^{\circ}$ (dashed lines) and $10^{\circ}$ (dot-dashed lines) between $z / L$ ratios from 0 to 3 (left). Results are based on the potential flow model. 
https://doi.org/10.5194/wes-2021-26

Preprint. Discussion started: 29 April 2021

(C) Author(s) 2021. CC BY 4.0 License.

\subsection{Influence of surface roughness}

The influence of roughness length on the lidar error has been analysed for the results from WAsP Engineering and Meteodyn WT for the three different used values of $0.005 \mathrm{~m}, 0.1 \mathrm{~m}$ and $0.5 \mathrm{~m}$. They are exemplarily shown for an $H / L$ ratio of 0.3 in Figure 7.

425 The general shape of the lidar error curve is comparable to that from the potential flow model. However, the maximum lidar error based on the WEng simulations exceeds that found with the potential flow model. Here the maximum value found at $z / L$ of 0.6 is about $-10 \%$, which is significantly larger than in the reference, especially for the lowest roughness. The estimated lidar error decreases strongly for smaller and larger $z / L$.

430 Figure 7 (right) shows the influence of the roughness length $z_{0}$ in Meteodyn WT. While the curve for the lowest roughness length has a pronounced maximum value and the shape of the curve is comparable to that from the potential flow, this is no longer the case for higher roughness length. For a $z_{0}$ of $0.1 \mathrm{~m}$, the lidar errors are generally smaller for all $z / L$ ratios, except the lowest two 0.2 and 0.3 . For these, the model results are very close to each other. At the maximum point, the lidar error is decreased by about 1 percentage point for the medium roughness length. The decrease of $\varepsilon$ is even stronger for a roughness

435 length of $0.5 \mathrm{~m}$. Here, $\varepsilon$ is decreased by another 1 percentage point for all $z / L$ ratios. However, the general shape of the error curve stays similar. For the highest roughness length, the lidar error decreased below $2 \%$ for a $z / L$ of 2.5 . 
https://doi.org/10.5194/wes-2021-26

Preprint. Discussion started: 29 April 2021

(c) Author(s) 2021. CC BY 4.0 License.
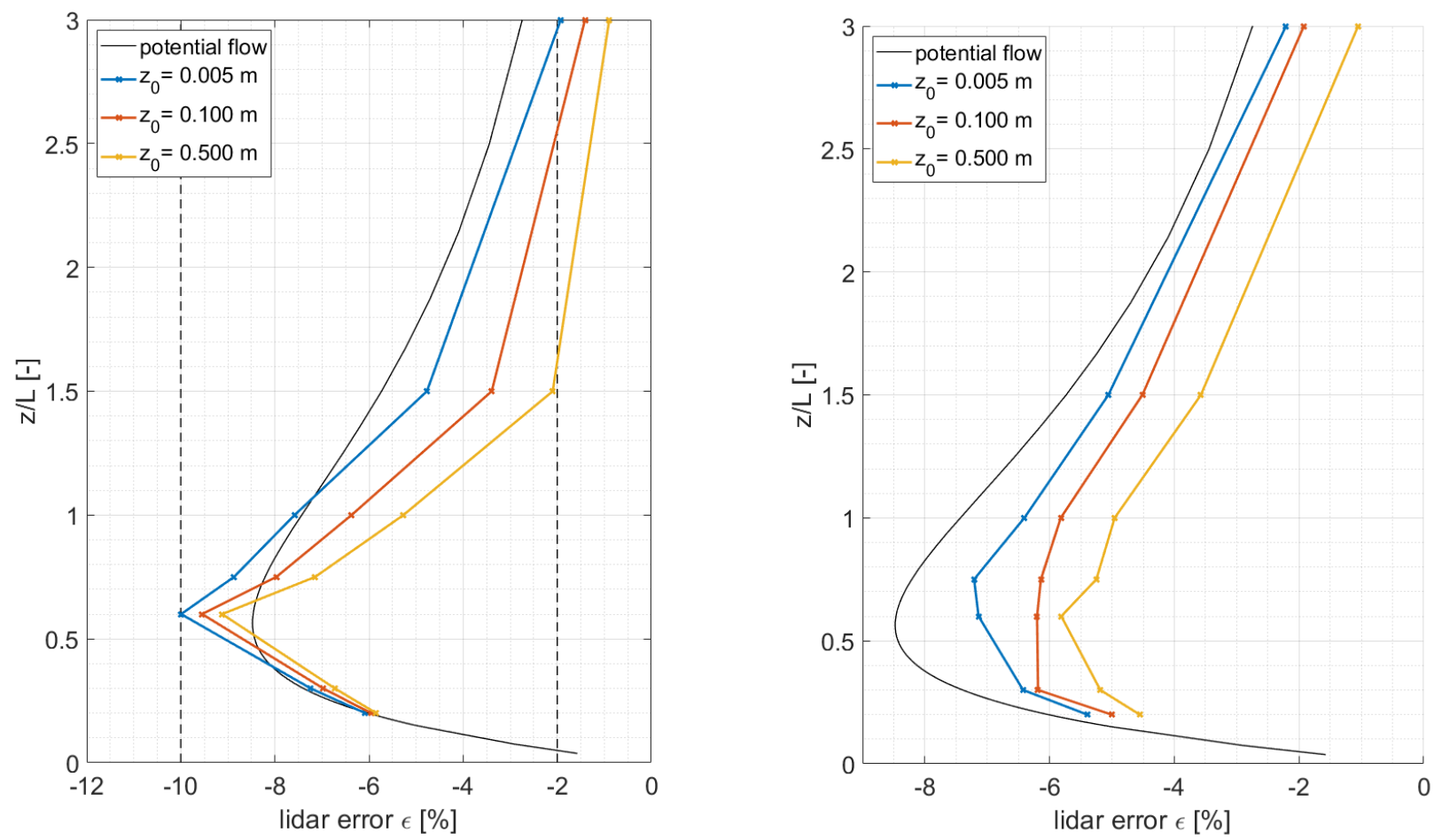

Figure 7: Model comparison between WAsP Engineering (left) and Meteodyn WT (right) for different roughness lengths for a $H / L$ ratio of 0.3. Lidar error $\varepsilon$ in dependence of the roughness length $z_{0}$ between $z / L$ ratios from 0 to 3 . Results from the potential flow model (black) are shown as a reference.

\subsection{Influence of forest}

Figure 8 (left) shows the impact of different tree heights on the total lidar error. The results are shown for a $H / L$ ratio of 0.3 , however the influence of the forest on the lidar error is different, depending on terrain inclination.

445 The total lidar error $\varepsilon$ shows a significant dependence on tree height. Highest lidar errors are found for small tree heights of $10 \mathrm{~m}$ and. When increasing the tree height to $20 \mathrm{~m}$ and $30 \mathrm{~m}, \varepsilon$ decreases for all $z / L$ ratios but the largest. Although maximum values for the lidar error can still be seen around $z / L$ ratios of 0.6 , the shape of the curves is not entirely comparable with that from the potential flow model as a reference. 

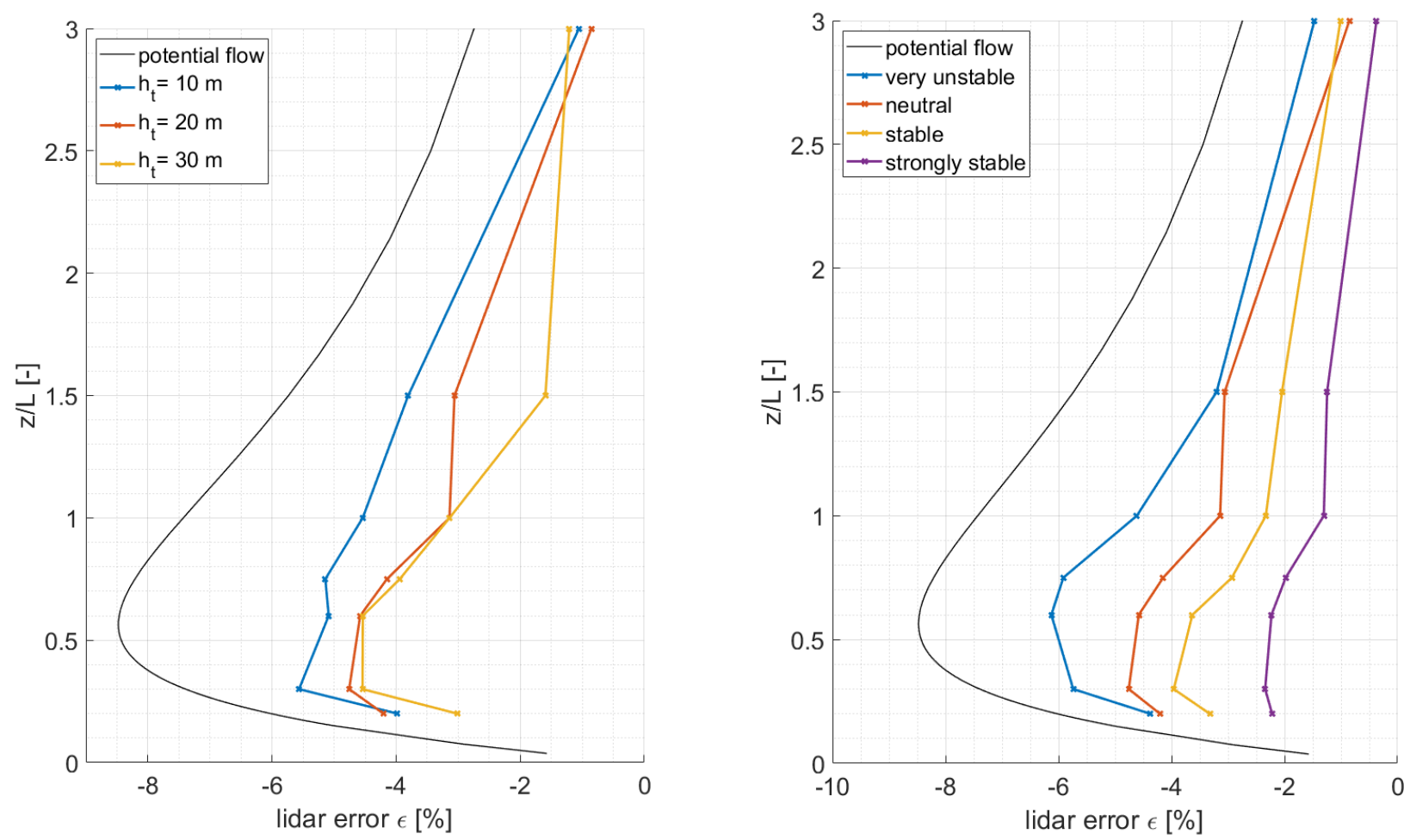

Figure 8: Lidar error $\varepsilon$ in dependence of tree heights $h_{t}$ (left) and atmospheric stability (right) between $z / L$ ratios from 0 to 3. Results are based on Meteodyn WT (colored) and the potential flow model (black) for an $H / L$ ratio of 0.3 . Results for different atmospheric stabilities are shown for the forested case with a tree height $h_{t}=20 \mathrm{~m}$ and medium forest density.

\subsection{Influence of atmospheric stability}

In order to analyze the influence of different atmospheric stability conditions, the stability class in Meteodyn WT has been modified for a part of the simulation cases. The influence of the stability parameter is most severe for medium to large $H / L$ ratios. The results presented in Figure 8 (right) sum-up these results for the four chosen stability classes very unstable, neutral, stable and strongly stable, exemplarily for a forested case and an $H / L$ ratio of 0.3 . These four out of ten possible stability classes in Meteodyn WT cover the whole possible range. Calculations have been carried out for all stability classes in-between those four, but the effects found are systematic and it is, therefore, sufficient to show only this excerpt.

A clear tendency of reduced lidar errors for increasing atmospheric stability can be seen. Largest lidar errors occur for very unstable stability conditions, with a clear maximum at a $z / L$ ratio of 0.6 and a lidar error $\varepsilon$ of about $-6 \%$. Coming to neutral, stable and strongly stable cases, the maximum is again shifted towards lower $z / L$ ratios. The maximum error for strongly stable cases is $-2.3 \%$ and can be found at a $z / L$ ratio of 0.3 . Below and above the maximum, there is a relatively sharp decrease 
https://doi.org/10.5194/wes-2021-26

Preprint. Discussion started: 29 April 2021

(C) Author(s) 2021. CC BY 4.0 License.

in lidar errors, which pronounces the maximum points. For the largest $z / L$ ratio of 3.0, the influence of atmospheric stability is relatively small.

\section{Conclusion}

Following a non-dimensional approach, the study allows for a comprehensive analysis of the effects of orographic complexity, measurement height, terrain roughness, forest, atmospheric stability as well as the half-cone opening angle of the lidar device on the resulting lidar error $\varepsilon$. Results and conclusions shown here do not represent the complete contents; the reader is therefore encouraged to study the full text of the dissertation for more and detailed information. Nonetheless, the presented results allow for a broad overview on the estimation of lidar errors in complex terrain by the use of flow models.

Unsurprisingly, the orographic complexity of the terrain, i.e. the $H / L$ ratio of the considered hill geometries has by far the most influence on the resulting lidar error estimations. For all models and parameterizations the lidar error significantly increases with increasing $H / L$ ratio. Depending on the flow model used, the lidar error becomes about 4-5 times larger when increasing the $H / L$ ratio from 0.1 to 0.4 .

Beyond that, the study introduces a novel approach that separates the total lidar error $\varepsilon$ into its parts $\varepsilon_{c}$ and $\varepsilon_{s}$ which are caused by flow curvature and local speed-up effects. Based on this concept, it becomes clear that under most circumstances both parts contribute significantly to the total lidar error. In any case, the major part is caused by flow curvature, i.e. $\varepsilon_{c}$. However, the actual share of $\varepsilon_{S}$ is dependent on the $z / L$ ratio and $10-30 \%$ of the total error can be attributed to local speed-up effects between the probe volumes. Resulting from this, error correction approaches for Doppler lidar profilers should always take into account both effects to minimize uncertainty in error estimations. Simplified approaches that rely solely on flow curvature or inclination might very well underestimate the total lidar error for specific terrain properties.

The non-dimensional concept of this study allows for a comprehensive assessment of the influence of measurement height on the lidar error. Initially, lidar errors strongly increase with increasing measurement height because the distance between the measurement points increases. Flow curvature and local speed-up effects come into play and both contribute to the total error. On the other hand, for very large measurement heights, the influence of the terrain on the overall flow field diminishes. As a trade-off between these two effects, maximum lidar errors occur at a $z / L$ ratio of approximately 0.6 . This complex interaction between measurement height and the actual terrain shape makes a detailed preliminary assessment of lidar errors for a measurement campaign at a given site and for the planned measurement heights mandatory.

Flow model parameterization has shown to be crucial for the estimation of lidar errors. This applies for terrain roughness, forest height and density as well as atmospheric stability and consequently for any combination of these. Generally speaking, 
rough and forested terrain decreases lidar errors. Correction approaches should therefore include forest models. From the results it can be concluded that, the potential flow and linearized flow models should only be applied for unforested sites with small low terrain inclinations. Under the presence of forest and especially for steep terrain inclinations, those models will significantly overestimate lidar errors, because they are not able to capture effects from e.g. flow separation in the lee of the hill. Atmospheric stability, in particular stable stratification, has significant influence on the lidar error estimation. Given a site with strong variations in atmospheric stability, this should also be considered in the lidar error estimation approach. However, these findings need to be researched in more detail in the future, especially under consideration of measurement data and information about atmospheric stratification.

In literature, the half-cone opening angle is usually considered to have negligible effects on the lidar error (Bingöl, 2009; Foussekis, 2009; Bradley, 2012). However, the concept of separating the total lidar error into a flow curvature and a speed-up part, it is possible to assess the impact of changing the half-cone opening angle in more detail. The analysis reveals opposed effects of decreased half-cone opening angles on $\varepsilon_{c}$ and $\varepsilon_{s}$. This explains the small influence on the total error that has been observed in other studies.

As an overall summary, it can be concluded, that the findings of this study clearly show that orographic complexity, roughness and forest characteristics, as well as atmospheric stability, have a significant influence on lidar error estimation. This study provides helpful guidance on the choice and parameterization of flow models as well as on the design of methods for lidar error estimation. The results emphasize that the use of a RANS CFD model in conjunction with an appropriate forest model is crucial to achieving reasonable lidar error estimations in complex terrain. If atmospheric stability variation at a measurement site plays a key role, the influence on the flow characteristics will also significantly affect the lidar error at those sites and should be considered in the modeling. In the context of a wind resource assessment, an accurate estimation of the prospective lidar errors should be carried out before the measurement campaign. It is then possible to make an early decision on whether a lidar measurement is feasible at the given site.

\section{Acknowledgements}

This paper is based on the detailed research within the doctoral thesis of the author (Klaas, 2020) . Both would not have been possible without the valuable discussions, advice and ecouragement from my supervisor Prof. Stefan Emeis. I would like to thank him very much for his support, patience and continuous enthusiam throughout this period.

I am also grateful for the support and feedback from my colleque Dr. Doron Callies when preparing the dissertation and this paper. 
https://doi.org/10.5194/wes-2021-26

Preprint. Discussion started: 29 April 2021

(c) Author(s) 2021. CC BY 4.0 License.

\section{References}

Antoniou, I., Courtney, M. S., Jørgensen, H. E., Mikkelsen, T., Hunerbein, S. V., Bradley, S., Piper, B., Harris, M., Marti, I., Aristu, M., Foussekis, D., and Nielsen, M. P.: Remote sensing the wind using Lidars and Sodars, 2007.

Ayotte, K. W.: Computational modeling for wind energy assessment, Journal of Wind Engineering and Industrial Aerodynamics, 96, 1571-1590, https://doi.org/10.1016/j.jweia.2008.02.002, 2008.

Basse, A., Callies, D., and Hahn, B.: Windmessungen und Windgutachten für die Standortbewertung von Windenergieanlagen an Land: Methoden und Analyse, Fraunhofer IWES, Kassel, 2017.

Behrens, P., O'Sullivan, J., Archer, R., and Bradley, S.: Underestimation of Monostatic Sodar Measurements in Complex Terrain, Boundary-Layer Meteorol, 143, 97-106, https://doi.org/10.1007/s10546-011-9665-6, 2012.

Belcher, S. E., Harman, I. N., and Finnigan, J. J.: The Wind in the Willows: Flow in Forest Canopies in Complex Terrain, Annual Review of Fluid Mechanics, 479-504, 2012.

Belcher, S. E., Finnigan, J. J., and Harman, I. N.: Flow through forest canopies in complex terrain, Ecological Applications, 1436-1453, 2008.

Bezault, C., Sanquer, S., and Nadah, M.: Correction tool for Lidar in complex terrain based on CFD outputs, in: EWEA 2012 Proceedings, edited by: EWEA, Brussels, 2012.

Bingöl, F.: Complex terrain and wind lidars, Dissertation, Risoe National Laboratory for Sustainable Energy, Technical University of Denmark, Roskilde, 2009.

Bingöl, F., Mann, J., and Foussekis, D.: Conically scanning lidar error in complex terrain, Meteorologische Zeitschrift, 18, 189-195, 2009.

Boquet, M., Parmentier, R., Sauvage, L., Cariou, J.-P., and Albergel, A.: Theoretical, CFD Analysis and Correction Methodology of Lidar Wind Profile Measurement in Complex Terrain, in: EWEC 2010 Proceedings, edited by: EWEA, Brussels, 2010.

Bradley, S.: A Simple Model for Correcting Sodar and Lidar Errors in Complex Terrain, J. Atmos. Oceanic Technol., 29, 1717-1722, https://doi.org/10.1175/JTECH-D-12-00106.1, 2012.

Bradley, S.: Wind speed errors for LIDARs and SODARs in complex terrain, IOP Conf. Ser.: Earth Environ. Sci., 1, 12061, https://doi.org/10.1088/1755-1315/1/1/012061, 2008.

Bradley, S., Strehz, A., and Emeis, S.: Remote sensing winds in complex terrain - a review, Meteorologische Zeitschrift, 547-555, https://doi.org/10.1127/metz/2015/0640, 2015.

Callies, D.: Analyse des Potenzials der Onshore-Windenergie in Deutschland unter Berücksichtigung von technischen und planerischen Randbedingungen, Dissertation, Universtität Kassel, Kassel, 259 pp., 2014.

560 Clifton, A., Clive, P., Gottschall, J., Schlipf, D., Simley, E., Simmons, L., Stein, D., Trabucchi, D., Vasiljevic, N., and Würth, I.: IEA Wind Task 32: Wind Lidar Identifying and Mitigating Barriers to the Adoption of Wind Lidar, Remote Sensing, 10, 406, https://doi.org/10.3390/rs10030406, 2018. 
Clive, Peter J. M.: Compensation of bias in Lidar wind resource assessment, Wind Engineering, 32, 415-432, 2008.

Courtney, M. S., Wagner, R., and Lindelöw, P.: Testing and comparison of lidars for profile and turbulence measurements in wind energy, IOP Conf. Ser.: Earth Environ. Sci., 1, 2008.

Dellwik, E., Landberg, L., and Jensen, N. O.: WAsP in the Forest, Wind Energy, 9, 211-218, 2006.

FGW e.V.: Technische Richtlinien für Windenergieanlagen Teil 6 (TR6): Bestimmung von Windpotenzial und Energieerträgen, Revision 10, Berlin, 60 pp., 2017.

Finnigan, J. J. and Belcher, S. E.: Flow over a hill covered with plant canopy, Q.J Royal Met. Soc., 130, 1-29, 2004.

Foussekis, D.: Operation of the Windcube V2 lidar at CRES Test Station, Pikermi, Greece, 2011.

Foussekis, D.: Investigating Wind Flow properties in Complex Terrain using 3 Lidars and a Meteorological Mast, in: EWEC 2009 Proceedings, edited by: EWEA, Brussels, 2009.

Gottschall, J., Courtney, M. S., Wagner, R., Jørgensen, H. E., and Antoniou, I.: Lidar profilers in the context of wind energy - a verification procedure for tracable measurements, Wind Energy, 15, 147-159, 2011.

Harris, M., Locker, I., Douglas, N., Girault, R., Abiven, C., and Brady, O.: Validated adjustment of remote sensing bias in complex terrain using CFD, in: EWEC 2010 Proceedings, edited by: EWEA, Brussels, 2010.

Jokela, T., Antikainen, P., Vignaroli, A., Öhrvall, F., Mannelqvist, T., and Eriksson, D.: Windcube Validation Measurements in Northern Sweden, in: EWEA 2013 Proceedings, edited by: EWEA, Brussels, 2013.

Kim, H.-G. and Meissner, C.: Correction of LiDAR measurement error in complex terrain by CFD: Case study of the Yangyang pumped storage plant, Wind Engineering, 41, 226-234, https://doi.org/10.1177/0309524X17709725, 2017.

Klaas, T.: Model-based study of the five main influencing factors on the wind speed error of lidars in complex and forested terrain, Universitäts- und Stadtbibliothek Köln, Köln, Online-Ressource, 2020.

Klaas, T., Pauscher, L., and Callies, D.: LiDAR-mast deviations in complex terrain and their simulation using CFD, metz, https://doi.org/10.1127/metz/2015/0637, 2015.

Krishnamurthy, R. and Boquet, M.: Case studies of WINDCUBE measurement uncertainty for complex terrrain unsing Flow Complexity Recognition, in: EWEA 2014 Proceedings, edited by: EWEA, Brussels, 2014.

Leo, L. S., Thompson, M. Y., Di Sabatino, S., and Fernando, H. J.S.: Stratefied flow past a hill: Dividing streanline concept revisited, Boundary Layer Meteorology, 611-634, 2016.

Leosphere: Windcube FCR measurements: Principles, performance and recommendations for use of the Flow Complexity Recognition (FCR) algorithm for the Windcube ground-based Lidar, Paris, 2017.

Mann, J., Ott, S., Joergensen, B. H., and Frank, H. P.: WAsP Engineering 2000, Roskilde, Denmark, 2002.

Meissner, C. and Boquet, M.: Correction of lidar remote sensing measurements by CFD simulations, in: EWEA 2011, Brussels, 2011.

Meteodyn: Software documentation, Nantes, France, 2014.

Meteodyn: Technical Note - meteodyn WT, Nantes, France, 2007. 
https://doi.org/10.5194/wes-2021-26

Preprint. Discussion started: 29 April 2021

(c) Author(s) 2021. CC BY 4.0 License.

(c) (1)

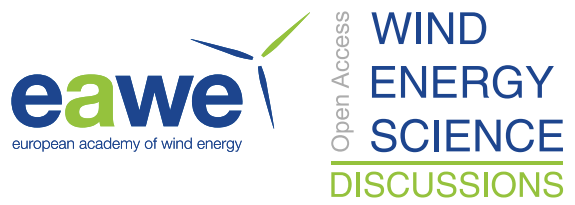

Palma, J.M.L.M., Castro, F. A., Ribeiro, L. F., Rodrigues, A. H., and Pinto, A. P.: Linear and nonlinear models in wind resource assessment and wind turbine micro-siting in complex terrain, Journal of Wind Engineering and Industrial Aerodynamics, 96, 2308-2326, https://doi.org/10.1016/j.jweia.2008.03.012, 2008.

Rohrig, K.: Windenergie Report Deutschland 2017, Fraunhofer-Institut für Energiewirtschaft und Energiesystemtechnik IEE, Kassel, 2018.

Ross, A. N., Arnold, S., Vosper, S. B., Mobbs, S. D., Dixon, N., and Robins, A. G.: A comparison of wind-tunnel experiments and numerical simulations of neutral and stratified flow over a hill, Boundary-Layer Meteorol, 113, 427459, https://doi.org/10.1007/s10546-004-0490-z, 2004.

Shannak, B., Träumner, K., Wieser, A., Corsmeier, U., and Kottmeier, C.: Flow characteristics above a forest using light detection and ranging measurement data, Proceedings of the Institution of Mechanical Engineers, Part C: Journal of Mechanical Engineering Science, 226, 921-939, https://doi.org/10.1177/0954406211417944, 2012.

Smith, D. A., Harris, M., and Coffey, A. S.: Wind Lidar Evaluation at the Danish Wind Test Site in Hoevsoere, Wind Energy, 9, 87-93, 2006.

Troen, I.: European wind atlas, Risø National Laboratory, Roskilde, Medienkombination, 1989.

610 Wagner, R. and Bejdic, J.: Windcube + FCR test in Hrgud, Bosnia \& Herzegovina Final Report, DTU Wind Energy, 40 pp., 2014. 